\title{
Clinical Stage IB Cutaneous Melanoma AJCC v8
}

National Cancer Institute

\section{Source}

National Cancer Institute. Clinical Stage IB Cutaneous Melanoma A/CC v8. NCI

Thesaurus. Code C137650.

Stage IB includes: (T 1b, N0, M0); (T2a, N0, M0). T1b: Tumor measuring less than 0.8 $\mathrm{mm}$ in thickness with ulceration, or 0.8-1.0 mm with or without ulceration. T2a: Tumor measuring more than 1.0 and equal to or less than $2.0 \mathrm{~mm}$ in thickness. Ulceration status: Without ulceration. N0: No regional lymph node metastasis detected. Presence of in-transit, satellite, and/or microsatellite metastases: No. M0: No evidence of distant metastasis. LDH level is not applicable. (AJCC 8th ed.) 